\title{
AC 2012-4073: BUILDING A COMPREHENSIVE SOLUTION TO OBTAIN AND SUSTAIN STUDENT LEARNING OUTCOMES FOR A COLLABO- RATED LAB
}

Mr. Fanyu F. Zeng, Indiana Wesleyan University

Fanyu F. Zeng is an Assistant Professor in business information systems at Indiana Wesleyan University. His research interests include software development, programming, database management, database performance, data mining, software project management, teaching methods, and international cultures in high education. 


\title{
Building a Comprehensive Solution to Obtain and Sustain Student Learning Outcomes for a Collaborated Lab
}

\begin{abstract}
Today's higher education teaches students that to know their subject matter and pass their exams are no longer enough. Students must obtain and sustain their knowledge for future practical problem solving from course work and lab exercise. To obtain knowledge is not easy task. Furthermore, to sustain knowledge from college study is an even more difficult, but critical and urgent task in the Chinese Information Technology Bachelor's program. This research tries to address this urgent need and discover a new way to ensure students to be able to obtain and sustain their learning outcomes from their course work through lab activity enhancement.

Today's college students come to their colleges with different motivations, goals, plans, attitudes, and expectations. College study requires them to complete all their assignments to reach all the goals with no requirement compromised. As a part of college study courses with computer lab assignments usually provide instructors with a unique opportunity to motivate students to work hard to achieve their goals and to sustain their knowledge as well as to measure student learning outcomes on this matter. Research finds it is still difficult to predict or measure how much students are able to sustain their learning outcomes before their graduations. This research aims to first ensure that all student lab activities and exercises are designed to not only for them obtain crucial knowledge and pass their course studies but to sustain their knowledge for a long term through newly designed lab activities. While student collaborations continue to stay in the center of their lab activities, additional new core of self-directed teaching and learning will engage students even deeply in their lab activity design in order to increase their interests and exposures to independently develop their knowledge in critical thinking and problem solving. Newly designed measurement and assessment for student learning outcomes is another nature product from this research.
\end{abstract}

This research recognizes importance and potential out of dramatically improving assessment on outcomes of lab activities as a part of coursework. As a part of an experiment it also selects methods and strategies from successful experience in American higher education and brings it into lab activity design by letting assessment goals lead the way of lab design. It engages both instructors and students in standard setting and determines when to vary targets or incorporate student work samples in standards. It is important to indicate that the standard setting is an ongoing process.

\section{Introduction}

Research studies previously conducted by the author and other researchers find that today's successful and innovative educational approaches must focus on critical thinking, logic reasoning, and problem solving. ${ }^{4,8,10}$ Higher education institutions in the US have made enormous efforts to adopt newly designed curricula and new techniques in teaching and learning in order to 
significantly improve student's learning outcomes and educate students to become well informed critical thinkers and deeply motivated problem solvers. ${ }^{4,10}$

A new issue rises up recently. Research finds that some college graduates are unable to sustain these knowledge and skills gained from their college study. ${ }^{4,8}$ This issue must be addressed immediately since today's fast growing economy often requires workers to become a selflearners in order to quickly adapt a new working environment. Educators and students must strive to make extra efforts to meet ever changing demands from rapidly changing business and working environment in this global economy.

The research for this Chinese Information Technology Bachelor's program believes that one of solutions to achieve all the educational objectives and sustain student knowledge for a long term is to develop learning experiences to meet student's educational and professional needs by encouraging student intentionality, discussion and involvement through lab demonstration, discussion, presentation, document co-creation, micro-sharing, peer critique, and evaluation. This belief helps determine the goal of this research is to identify and test new teaching and learning methods to effectively improve and sustain student learning outcomes. The fundamental change in this research is to shift students from passive learners to be their own masters in lab design, implementation, and assessment. New teaching and learning methods in this experiment in this research include student's active participation in lab activity design and assessment process. Experiment outcomes must be carefully evaluated by newly designed assessment and explored for future experiment.

\section{Higher Education Requires Innovative Solutions for Student Knowledge Sustainability}

Today successful course curriculum design in higher education always aims to engage students into all activities both inside classroom and outside classroom. ${ }^{8,14}$ However, student self-directed lab activities often do not get recognized as an important component in some curricula. ${ }^{1}$ To address this issue there must be a new innovative solution added to student lab activity design to engage students into their learning activities and hold them more accountable to their learning outcomes. ${ }^{1,13}$ This new solution focuses on stimulating student's intentionality, encourage their participation and involvement through self-learning, sharing, and motivating. Most importantly students will master their own ways to design a learning process, manage interactions inside classroom and particularly in all lab activities, and conduct evaluation and assessment in order to develop student learning experience to a higher level. In addition, a standard setting is also included as a crucial solution to ensure that same standard and measurements are always applied

in the assessment and evaluation for newly added student learning. ${ }^{14}$

The main focus of the new solution is that student learning experience must be enhanced to meet student's future educational and professional needs. Previous research finds that certain knowledge can soon become outdated or even obsolete while other knowledge can be crucial and beneficial to student's professional career for a long run. ${ }^{8,10}$ Students can obtain those crucial knowledge in critical thinking and problem solving from college study and sustain the knowledge for their professional career through newly developed enhancement. In order to sustain student knowledge in critical thinking and problem solving, one of suggested changes is 
for students to take their ownership of the course design and control their knowledge and experience development while sharing their educational responsibilities with their instructors. ${ }^{4,8}$

Furthermore, incorporating student learning results into standardized assessment process helps students understand the difference on accountability between personal and professional learning experience to model their future professional practices. ${ }^{4,7}$ In the past a number of researches discover that student personal learning experience must model professional practices as a part of student learning need change. ${ }^{10}$ Based on these research findings a set of new changes are selected to incorporate students in standard classroom activities such as activity design, assignment design, classroom discussions, group study, and final measurement and assessment.

This research hypothesizes that the newly designed lab activities will help reach the goal to sustain student knowledge for their later professional career. To ensure that this change has achieved sustainability objective standardization of assessment process becomes a crucial part of this change. The assessment helps design standardized measurement and procedure for activities in a lab and measure whether or not all the objectives are reached through these activities. A standard setting is an ongoing process as student needs and course content and goals are constantly changing.

This research also plans to experiment proper ways to maximize usage of assessment data and incorporate learning results into the assessments to further help students understand different accountabilities between personal and professional learning environments.

\section{New Lab Activity and Assessment Standard Design for Student Knowledge Sustainability}

Development of innovative knowledge for sustainability reflects on individual and organizational strategies that could facilitate a more adaptive learning process for sustainability. ${ }^{3,9}$ The traditional linear model of science and society that informs our academic enterprise is not conducive to dealing with the dynamic global economy changes that sustainability entails, and the way that these in turn influence what knowledge is necessary. The linear model assumes that academics need only to pursue their research agenda without input from industry. This research uses it as a fundamental guideline and focuses on discovering a new way to modify the existing linear model and create a positive impact on student knowledge sustainability development.

Although traditional approaches are still valuable to the pursuit of knowledge, they are missing key components to build knowledge for sustainability: reflexivity and epistemological pluralism. Reflexivity shatters the linear model by including economy and industry in the production of knowledge to the point where such involvement may fundamentally alter the type of and ways in which knowledge is produced. ${ }^{3,9}$ In order for students to accommodate their future professional career and to sustain student's knowledge significant changes area adopted while working in the context of academic institutional constraints and balancing the production of more stable, disciplinary knowledge with innovative knowledge for sustainability. ${ }^{6}$

Building student's knowledge for sustainability indeed brings both students and faculty into a completely different field. Previous research finds one of most effective solutions is to engage students with each other and with their instructors in the development of their knowledge 
sustainability. ${ }^{9}$ The unique blend of personnel has a profound effect on the way we work across academic disciplines and approach real world problem solving. College courses and activities in these courses attempt to build knowledge for sustainability that will contribute to solutions for real world's problems. ${ }^{3,9}$

The new process to design lab activities specifically benefits from these discoveries in the researches. It focuses on how to engage and interact with students through several practical strategies. Its key element is for students to be actively involved in making plans for organizing material before confronting a course management system and determine guidelines for estimating lab objectives, contents, load, and time for each lab element. It develops an efficient system for re-designing face-to-face labs and suggests that structuring lab activities is essential to improve student's comprehension of their learning objectives and sustain their knowledge gains from these activities.

This research also discovers the best way to facilitate communication through various channels is to work effectively with students on developing lab activity plan and keep lab activity design from interfering with other responsibilities. It is an effective timesaving method for receiving student feedback with various communications channels versus traditional classroom teaching design methodology.

This research tries to identify student's strengths and weaknesses in all lab activities and discover where student learning curve locates. Their weakness is expected to be improved by inviting their active participation into effective lab activity design by injecting student's personality, engaging and interacting with other students and pulling content from students with instructor's supervision.

The last new and important component determined by this research is the principles of sound assessment to be applied in student lab learning outcome evaluation. The new assessment must differ from traditional assessment with new ways to prioritize learning objectives and student's participation. Most importantly the assessment is to apply performance assessments in a new lab setting to provide transparent evaluative criteria. ${ }^{5,7}$ The criteria include:

- how to design effective performance tasks

- whether new approach and methodology save time while improving feedback

- completion of new feedback and discussion options

- how to use new rich media to turn students into "instructors" and promote self-learning and mutual learning

- how student teaching modules can facilitate other student's learning

- how to maximize uses of student learning motivations in their personal learning environments outside their classroom and lab.

This research recognizes importance of standardizing course lab design and designs its own assessment standard and benchmark after analyzing and evaluating advantages and disadvantages of various assessment standard and benchmark. New standard and benchmark is suitable to classroom lab setting and make course assessments easy to measure individual student performance and targets for collective student performance on knowledge sustainability. 
The proposal for the assessment standard also enables instructors to analyze and apply their assessment results to help convey strengths and accountability and also to identify areas that need improvement. Assessment results work the same way with predetermined context or point of comparison to evaluate student learning performance and further improve benchmarks or standards as benchmark and standard setting is an ongoing process. ${ }^{1,13}$

\section{Implementation with Newly Designed Student Lab Activities and Assessment}

Building a comprehensive student learning model for their lab activities must first recognize characteristics of today's self-learners, how they affect their learning and identify environments supporting effective teaching and learning for today's students and compare current learning environments with what works for next generation learners. ${ }^{12}$

This research examines all the assignments and their assessments in light of learner's needs and preferences before implementation starts. The core of this implementation is self-directed learning method to develop student's ability of taking multiple roles in a lab design and using multiple resources to share and engage students in all activities. This helps develop their critical thinking capability and increase their interests in independent problem-solving and in a team effort format as well.

Previous research suggests that in learner-centered teaching and learning environment the role of an instructor may change. ${ }^{2}$ A new experiment forces instructors make their transitions from the disseminator of information to the creator of questions designed to facilitate student learning. This switch from lecturer to question creator is an important step in the developing evolution of pedagogical expertise. When students are deeply involved in a course as well as their lab activities, the research expects that it will significantly improves the success rate of sustaining student learning outcomes.

A design team is formed and both instructors and students in the design team are actively involved in lab activities design. Another new idea is to use stable base groups and new standards to create problems in their lab and solve problems in their lab. This seemed to be a perfect solution to help organize the lab activities and ensure to yield better than expected learning results.

To put it into practice new standards for lab activities are proposed by the design team and these new standards include:

- sample documents

- $\quad$ self-assessment questions

- rubrics

- further discussion questions

- blank worksheets

- additional resources

- discussion guide for facilitators to help students implement what they want to learn.

Measuring learning outcomes is recognized challenging enough in a traditional classroom setting. When measurement and standard for lab activities are designed, it can be even more confusing or 
challenging. ${ }^{3}$ Common questions include "How can we

- assess an individual and team effort?

- create meaningful performance tasks?

- deliver effective feedback without writing in the margins of assignments?"

The key to succeeding with designing new assessment for lab activities is embracing the opportunities of the new technology and methods. While some new forms of assessment are not effective at beginning, this loss is more than offset by innovative and alternative ways of finding evidence of learning. Many familiar forms of assessment don't work well or at all in the new lab activity format. Assessing student's lab activities requires fresh thinking, new ideas, and a willingness to embrace the latest technologies and methods for measuring learning in a course lab environment.

New lab assessment engaging students in end of course survey questions has become real nutrition of the course because new learning method let students become active learners and instructors as well. It effectively engages students in thinking about the course content once again and provides a platform to encourage students to look at the course material prior to coming to lab and review what they have learned from their classroom because they will be asked questions about the material as soon as they walk into their lab.

This experiment also tries to use new evaluation methods occasionally to take a break from lecture. The more advanced use is to design lab activities around course activities such as preclass quizzes, pre-class assignments, groups in class, and mini-lectures during class. With help of new lab activities both instructors and students make a commitment to student critical thinking and more importantly students are almost always "on" in their lab. Students are no longer passively taking notes. Instead the students are using their cognitive skills to connect information necessary to answer a specific question and they maintain this cognition throughout the class period. It is interesting to discover that students tend to get overly excited about their learning.

At first glance, evaluating student's activities in a lab may seem more difficult and timeconsuming. Closer examination, however, reveals an exciting array of assessment possibilities that can actually improve learning while giving student more control of their study and reducing faculty involvements. The new capabilities of student driven lab design can even help elevate students from passive recipients of information to active participants in constructing knowledge. Another benefit from classroom observation is the potential for dramatically improving learner's assessment in new lab environment. Students discover the newest strategies for designing better lab activities by letting assessment goals lead the way.

Students experience adopting proper strategies and principles of sound assessment apply to new lab learning environment. They also learn

- new assessment differs from traditional assessment

- new ways to prioritize their learning objectives

- how to apply performance assessments in a student driven lab environment

- new ways to provide transparent evaluative criteria

- how to design effective performance tasks 
- how to adopt new technologies that save time while improving feedback

- new feedback and discussion options, including Instant Messaging and blogs to turn students into "teachers" and promote learning

- how student teaching modules can facilitate learning

- how proper assessment transforms the entire learning process

\section{Limitations of the Study}

This research mainly develops a new addition to an existing course framework with new focus on student's learning activities design and student involvement in their lab activities.

Quantitative data collection and data analysis plan have not completed yet. Preliminary analysis and findings are mainly from author's observation and analysis on limited qualitative data in student's end of course survey. It is possible that actual results from in-depth data analysis may be different from author's finding or final statistical analysis may not support original hypothesis. It is author's hope that preliminary analysis will confirm effectiveness of this change in order to stay on a right direction to achieve most of original goals. Since it is still difficult to predict complete and accurate outcomes at this moment, a statistical analysis on a larger student sample would be necessary to confirm and support the original hypothesis and findings from this experiment in the future.

\section{Conclusion}

New lab activities design provides a springboard for both instructors and students to revolutionize the way they think about teaching and learning. One significant change is students have become self-learners and are able to identify their future educational needs, make their own learning plan accordingly, and execute their learning effectively and independently to meet their future educational and professional needs.

Benefits seem unlimited. A significant benefit is student's engagement boost student's motivations in their learning process. Students practice how to determine proper ways to achieve their learning goals. Their plan and execution of learning require them to learn from peers and further develop their communication skills. Student's participation also makes them become aware of their goals and how to reach these goals. Their new responsibilities in a course development and execution develop their critical thinking skills. The specific strategies and techniques often train students to learn how to manage their lab activities and conduct evaluation and assessment on these activities thereafter. Adopting new standardization in assessment practices help students become effective educators and critical thinkers as well.

New design for student lab activities seems to enhance student engagement, motivate their learning, and provide them with a new array of opportunities to obtain and sustain their knowledge gained from their college education. It confirms possibility of developing and implementing advanced curriculum for a lab in addition to course itself. The lesson learned from the experiment has laid out a solid foundation for future improvements and experiments with a larger student sample size.. 


\section{Bibliography}

1. Chan, C. and Fok, W., "Evaluating learning experiences in virtual laboratory training through student perceptions: a case studyin Electrical and Electronic Engineering at the University of Hong Kong", http://www.engsc.ac.uk/journal/index.php/ee/article/viewPDFInterstitial/136/195.

2. Chen, L. and Lin, C., "Combining Theory with Practice in Information Security Education", http://csis.pace.edu/ lchen/papers/TheoryintoPractice.pdf.

3. Cushman, M., Venters, W., Cornford, T., and Mitev, N., "Understanding Sustainability as Knowledge Practice", http://www.c-sand.org/Documents/BAM2002.pdf .

4. Dansberry, B., "DEFINING THE IMMEDIATE LEARNING OUTCOMES OF AN UNDERGRADUATE INTERNSHIP PROGRAM", AC 2009-491, in Proceedings of the 2009 ASEE Annual Conference, Austin, TX, June 14-17, 2009.

5. DeFranco, J., Deek, F., Sangwan, R., "PROMOTING EFFECTIVE COMMUNICATION IN GLOBAL ENGINEERING PROJECTS", AC 2010-25, in Proceedings of the 2010 ASEE Annual Conference, Louisville, KY, June 20-23, 2010.

6. Geddes, J., Wilding, W., Lewis, R., "SUSTAINABILITY AND IMPACT OF GLOBAL PROJECTS", AC 2009-484, in Proceedings of the 2009 ASEE Annual Conference, Austin, TX, June 14-17, 2009.

7. Hahn, L., Hansen, A., "Learning Outcomes Assessment Of A Project-Abroad Program in South Africa: Toward “A Better Engineer In The Real World"”, AC 2009-577, in Proceedings of the 2009 ASEE Annual Conference, Austin, TX, June 14-17, 2009.

8. Harlow, N., Choate, R., Lenoir, H., "EXTRACURRICULAR PROJECT ENHANCES STUDENT LEARNING: A CASE STUDY", AC 2010-145, in Proceedings of the 2010 ASEE Annual Conference, Louisville, KY, June 20-23, 2010.

9. Muñoz-Erickson, T. and Miller, T. "Student's Perspective on Building Knowledge Sustainability", http://www.thesustainabilityreview.org/2010/03/students-perspective-on-building-knowledge-forsustainability/.

10. Samples, J., "LEADERSHIP 107: STUDENT CENTEREDNESS - A BALANCE", AC 2010-1211, in Proceedings of the 2010 ASEE Annual Conference, Louisville, KY, June 20-23, 2010.

11. Sharp, J., and Dyrud, M., "TWO PERSPECTIVES ON PEER REVIEW", AC 2009-420, in Proceedings of the 2009 ASEE Annual Conference, Austin, TX, June 14-17, 2009.

12. Soma, M. and Riskin, E., University of Washington, Seattle, WA, "A hands-on laboratory-driven Electrical Engineering 2-year curriculum for distance and at-home learning", http://www.ee.washington.edu/faculty/soma/fipse/.

13. UC Berkeley, "Online curricula for monitored, closed-lab first-year CS courses", http://www.cs.berkeley.edu/ clancy/ucwise/ccliemd04_narrative.pdf.

14. Velankaris, Y., Brophy, S., Okutsu, M., Delaurentis, D., "TEAM-BASED NEGOTIATION OF IDEAS ON DESIGN DECISION MAKING PERFORMANCE”, AC 2010-1902, in Proceedings of the 2010 ASEE Annual Conference, Louisville, KY, June 20-23, 2010. 